\title{
Theft of virtual items in online multiplayer computer games: an ontological and moral analysis
}

\author{
Litska Strikwerda
}

Published online: 6 January 2012

(C) The Author(s) 2012. This article is published with open access at Springerlink.com

\begin{abstract}
In 2009 Dutch judges convicted several minors for theft of virtual items in the virtual worlds of online multiplayer computer games. From a legal point of view these convictions gave rise to the question whether virtual items should count as "objects" that can be "stolen" under criminal law. This legal question has both an ontological and a moral component. The question whether or not virtual items count as "objects" that can be "stolen" is an ontological question. The question whether or not they should count as such under criminal law is of a moral nature. The purpose of this paper is to answer both the ontological question and the moral question underlying the legal question.
\end{abstract}

Keywords Virtual - Institutional reality . Computer games - Theft - Harm principle

\section{Introduction}

In 2009 Dutch judges convicted three minors of theft for the stealing of virtual furniture in the virtual world of the online multiplayer computer game Habbo (Rechtbank Amsterdam, 2 April 2009, LJN: BH9789, BH9790, BH9791). Habbo consists of a virtual hotel where players have their own room, which they can furnish. By means of deceit the perpetrators obtained the usernames and passwords of other Habbo players, so that they could access the other players' accounts and transfer their virtual furniture to their own Habbo accounts.

L. Strikwerda $(\bowtie)$

Department of Philosophy, University of Twente, P.O. Box 217,

7500 AE Enschede, The Netherlands

e-mail: L.Strikwerda@utwente.nl
In a similar case, two minors were convicted of theft for stealing a virtual amulet and a virtual mask in the virtual world of the online multiplayer computer game RuneScape (Gerechtshof Leeuwarden, 10 November 2009, LJN: BK2773, BK2764). RuneScape is a virtual medieval fantasy realm in which players earn points and items, such as the aforementioned amulet and mask, through their activities in the realm. The perpetrators had violently forced another player of RuneScape to give them access to his account, so that they could transfer his virtual amulet and virtual mask to their own RuneScape accounts. The highest court of the Netherlands (Hoge Raad) will decide on the RuneScape case, but the decision is still pending.

From a legal point of view the RuneScape and the Habbo cases raise the question whether virtual items, such as a virtual mask, a virtual amulet and virtual furniture, should count as "objects" that can be "stolen" under criminal law (Hoekman and Dirkzwager 2009, p. 158). This legal question has both an ontological and a moral component. The question whether or not virtual items count as "objects" that can be "stolen" is an ontological question. As will be explained below, the question whether or not they should count as such under criminal law is largely of a moral nature.

In liberal societies the criminal law is seen as a last resort. Since the punishments of the criminal law, e.g. deprivation of liberty, represent grave infringements of the fundamental rights of persons, it is only considered justified to apply the criminal law if no less intrusive alternatives seem reasonable (Murphy and Coleman 1990, pp. 109-110). Although legal policy considerations might also play a role, the decision whether it is reasonable to apply the criminal law or a less intrusive alternative is mainly based on moral grounds. In essence, it is only morally appropriate to use criminal law to control the infliction of harm within society (Brenner 2008, p. 5). 
Lawyers have extensively debated the legal question raised by the RuneScape and Habbo cases, in- as well as outside the Netherlands (e.g. Hoekman and Dirkzwager 2009; Moszkowicz 2009; Rijna 2010; Brenner 2008; Kerr 2008). The purpose of this paper is to answer both the ontological question and the moral question underlying the legal question. In this way I hope also to contribute to the legal debate; for I think that the answers to these questions are relevant for the ultimate answer to the legal question. My main aim, however, is to put the issue of theft of virtual items on the agenda of computer ethics, because I think that it is in need of further discussion and analysis by scholars in this field. I hope this paper provides a fruitful starting point.

I will begin with the ontological question. I hold that the act of stealing in the virtual world of an online multiplayer computer game can be seen as a "real institutional activity" and virtual items as "requisite objects" if they have the features that make it sensible to see them as such (Brey 2003, pp. 278-279). Applying Searle's "constitutive rule" (Searle 1995, pp. 28, 46), it can be said that the act of stealing in the virtual world of an online multiplayer computer game $(\mathrm{X})$ counts as theft $(\mathrm{Y})$ in the non-virtual world (C). Thereby, it is admitted that virtual items (X), count as "objects that can be stolen" $(\mathrm{Y})$ in the non-virtual world (C). Ultimately, I come to the conclusion that it also makes sense, from a moral point of view, to count the act of stealing virtual items in the virtual world of an online multiplayer computer game as theft and, thereby, virtual items as "objects" that can be "stolen" if these virtual items can be considered property with (pecuniary or hedonistic) value in the non-virtual world. If so, the act of stealing them harms: it makes the owner worse off in a way which affects his well-being. It is widely accepted that, from a moral point of view, it is legitimate to bring an act under the scope of a penal norm if it is harmful to others (Mill 1865, p. 6).

\section{Ontology in the virtual worlds of computer games}

The virtual entities encountered in the virtual worlds of online multiplayer computer games such as Habbo or RuneScape can be divided into two main categories. These virtual entities can be representations of real entities; in the virtual world of a computer game one can, for instance, encounter a virtual chair or a virtual car. One might also encounter virtual entities that do not have a real, non-virtual counterpart, such as a virtual dragon or a virtual gnome. These entities are not only virtual; they are also fictitious. According to Brey the first category of virtual entities, the representations of real entities, can be further categorized as follows. He thinks that they are either "mere simulations of real-world entities" or "genuine ontological reproductions, recognized as part of reality" (Brey 2003, p. 282).

The virtual representations of real entities that have certain essential physical properties, such as mass, are mere simulations. The virtual counterparts of such real entities are not recognized as part of reality, because computers are evidently "not able to reproduce their essential physical properties" (Brey 2003, pp. 277-278). Consider the following example. Although producer Polyphony claims that its new computer game Gran Turismo 5 provides a real driving experience (http://www.gran-turismo.com), driving a car through the mountains in the virtual world of Gran Turismo 5 is not normally interpreted as a real experience, but as a mere simulation, because computers are not able to reproduce the essential physical properties of a car (e.g. the mass) and mountains (e.g. the height). The virtual representations of real "institutional" entities can be genuine ontological reproductions, recognized as part of reality. Below, it will be explained what institutional entities are and why they can be adequately ontologically reproduced in virtual environments.

The concept of institutional entities derives from Searle. By institutional entities Searle means entities on which some "status function" has been imposed (Searle 1995, pp. 14, 27-29). Status functions are imposed when people collectively assign a status to an entity. The collective assignment of status results in an agreement, which has the form of the following "constitutive rule": " $X$ counts as $Y$ in context C" (Searle 1995, p. 28). Here, X defines the entity that is assigned a status, $\mathrm{Y}$ defines the status that is assigned and $\mathrm{C}$ defines the context in which this status holds. Money is a good example of an institutional entity. We have collectively agreed, for instance, that the Euro (X) counts as a legal tender $(\mathrm{Y})$ in certain EU membercountries, which are collectively known as the "Eurozone" (C).

As Brey points out, institutional entities can be adequately ontologically reproduced in virtual worlds, because they usually do not need to have physical properties of the kind that cannot be reproduced by computers. "In principle, any status function can be assigned to anything, if only there is the collective will to do it" (Brey 2003, p. 278). However, in practice, people will only assign status functions to entities that have the features that make it sensible to do that (Ibid.).

According to Brey many real institutional entities are ontologically reproduced in virtual environments nowadays, because there are "many virtual entities that lend themselves well to the meaningful assignment of status functions" (2003, pp. 278-279). He divides the virtual counterparts of real institutional entities into two categories: "real institutional activities" and "requisite objects" (Ibid.). Online gambling is an example of a real 
institutional activity; a virtual slot machine is an example of the requisite object. The act of online gambling on a virtual slot machine $(\mathrm{X})$ counts as gambling $(\mathrm{Y})$ in the nonvirtual world (C), or at least it makes sense to count it as such if one can really win or lose money.

Yet the question arises as to which category the virtual mask, virtual amulet and virtual furniture that were at stake in the RuneScape and Habbo cases belong. These virtual entities are not fictitious; they are representations of real entities. At first glance one would say that they belong to the subcategory of virtual entities that are mere simulations of real entities, because computers are evidently not able to ontologically reproduce the essential physical properties of furniture, a mask or an amulet, such as their mass. If one looks at them from a legal perspective, however, one can argue that the virtual mask, virtual amulet and virtual furniture that were at stake in the RuneScape and Habbo cases are genuine ontological reproductions, recognized as part of (institutional) reality. The judges in these cases seem to have assumed that the act of stealing in the virtual world of RuneScape or Habbo is a real institutional activity. In line with Searle's "constitutive rule" they have recognized that the act of stealing in the virtual world of these online multiplayer computer games (X) counts as theft $(\mathrm{Y})$ in the non-virtual world $(\mathrm{C})$. They have, thereby, also recognized that the requisite objects, a virtual mask, virtual amulet and virtual furniture (X), count as "objects that can be stolen" ( $\mathrm{Y})$ in the non-virtual world (C).

As mentioned earlier, Brey claims that status functions are usually only assigned to virtual entities that have the features that make it sensible to do that (2003, p. 278). The Habbo and RuneScape cases raise the question whether it makes sense to see the act of stealing in the virtual world of an online multiplayer computer game as the real (ontologically reproduced) institutional activity of theft and virtual items as requisite objects (objects that can be stolen). Answering these questions will be the aim of the following sections.

\section{Stealing in the virtual world of an online multiplayer computer game, real theft?}

I will start with the question whether it makes sense to see the act of stealing in the virtual world of an online multiplayer computer game as the real institutional activity of theft. As was briefly mentioned in the introduction, it is mainly decided on the basis of moral grounds whether it is reasonable to bring an act under the scope of a penal norm or not. Therefore, I will examine the aforementioned question from a moral point of view. In order to gain as broad a picture as possible, I will make use of different models of moral reasoning.
At first glance, the "top-down model" of moral reasoning seems the best way to find the answer to the question at stake. In a top-down model of moral reasoning it is established whether a new, particular situation falls under a general rule. A general rule can for instance consist of a principle, a norm or an ideal (Beauchamp 2003, p. 7). In this case, it needs to be established whether the act of stealing in the virtual world of an online multiplayer computer game falls under the prohibition of theft, which is a (penal) norm.

Many lawyers argue that (criminal) law should not be applied to the virtual worlds of computer games (e.g. Brenner 2008; Kerr 2008; Moszkowicz 2009; Rijna 2010). They think that there is a kind of metaphorical line, a "magic circle", between the fantasy realms of the virtual worlds of computer games and the non-virtual world (Fairfield 2009, p. 824; Salen and Zimmerman 2004, pp. 93-100). The concept of the magic circle originally derives from the Dutch philosopher Huizinga (1950 [1938]). The thrust of the magic circle is that conduct that is performed in a (computer) game setting is not real and can therefore not be sanctioned by real law (Fairfield 2009, p. 825).

There does indeed seem to be a magic circle. In the virtual worlds of computer games players often act out scenarios that would fall under a penal norm if performed in the non-virtual world (Fairfield 2009, p. 826). In the virtual world of the computer game Grand Theft Auto, for instance, players can kill policemen (http://www.rock stargames.com/ grandtheftauto). An actual murder charge has never been brought against a player who killed a policeman in Grand Theft Auto, however.

The magic circle can be explained as follows. The virtual worlds of computer games are, usually, governed by the rules of the game. Some of them, e.g. Habbo and RuneScape, are governed by "formally generated rules", which are set by the company that owns and operates the computer game and to which players have to agree before they can play the game. The virtual worlds of other computer games, e.g. Second Life, are governed by "informally generated rules", which are agreed upon by players themselves (Fairfield 2009, pp. 831-832). As long as players act out scenarios that fall under the scope of these rules, there is no room for legal regulation (Ibid., p. 826). An undesirable act can then be sanctioned by a punishment set by the company that owns and operates the computer game or a punishment on which the players have collectively agreed. On the other hand, if a player acts out a scenario that does not fall under the scope of the (formally or informally generated) rules of the game, the metaphorical line of the magic circle is crossed and the act might, therefore, be subjected to (penal) law instead (Ibid., pp. 831-832). 
Computer games can be compared to sports, such as soccer, with regard to this matter. During a soccer game players often perform acts, such as kicking an opponent player, that would fall under a penal norm (e.g. battery) if performed in a different context. In the context of a soccer game, however, the aforementioned behaviour will usually be governed by the rules of the game and the player will, for instance, be shown a yellow or a red card. But, as the following example shows, an act performed during a soccer game can exceed the rules of the game and, therefore, be subjected to penal law instead. In 2004 a Dutch soccer player committed a foul on an opponent player and thereby caused his leg to break in several places. He was convicted of battery under criminal law (Hoge Raad, 22 April 2008, LJN: BB7087). The judges in this case established that there are two types of situation in which an act performed in a game context does not fall under the scope of the rules of the game. First of all, an act can constitute such a grave violation of the rules of the game that they do not provide an adequate punishment. Secondly, an act can be (partly) performed outside the game setting (Hoge Raad, 22 April 2008, LJN: BB7087, § 4.5).

The first type of situation was at stake in the case at hand: even the most severe punishments of the soccer rules, penalty and expulsion, are not proportional to a compound leg fracture. This type of situation could also occur in the context of an online multiplayer computer game. Consider the following example. Some online multiplayer computer games, e.g. Habbo and RuneScape, provide a chat interface. Generally, the rules of these computer games prohibit the use of racist language. Players who break this rule face a penalty, usually in the form of a (temporary) ban or mute (http://www.runescape.com, http://www.habbo.nl; http:// www.habbo.com). But if a player uses racist language that is found to be so offensive that a (temporary) ban or mute is not considered to be a proportional punishment, a penal norm, e.g. the prohibition on hate speech, might be applied instead.

As the judges in these cases explain, the second type of situation was at stake in the Habbo and RuneScape cases (Rechtbank Amsterdam, 2 April 2009, LJN: BH9789, BH9790, BH9791; Gerechtshof Leeuwarden, 10 November 2009, LJN: BK2773, BK2764). The acts of stealing in Habbo and RuneScape were partly performed outside the setting of these games, because they involved out of the game infractions. In the Habbo case, the act of stealing was accomplished through out of the game deceit. The perpetrators had used phishing techniques to create a false website and to trick other players of Habbo into providing their usernames and passwords, so that they could access the other players' accounts and transfer their virtual furniture to their own Habbo accounts (Rechtbank Amsterdam, 2 April 2009, LJN: BH9789, BH9790, BH9791). In the RuneScape case, the act of stealing was accomplished through a physical confrontation in the non-virtual world. The perpetrators had violently forced their victim to give them access to his account so that they could transfer the virtual amulet and virtual mask to their own accounts. They had hit and kicked him and threatened him with a knife (Gerechtshof Leeuwarden, 10 November 2009, LJN: BK2773, BK2764).

The determination that an act in the virtual world of an online multiplayer computer game does not fall under the scope of the rules of the game and, therefore, crosses the metaphorical line of the magic circle is a necessary, but not a sufficient condition to subject this act to penal law. For the purpose of applying the criminal law it is also important whether the act caused harm. For it is widely accepted that an act should only be brought under the scope of a penal norm if it falls under John Stuart Mill's "harm principle" (Steel 2008, p. 716). The harm principle entails “(...) that the only purpose for which power can be rightfully exercised over any member of a civilised community, against his will, is to prevent harm to others" (Mill 1865, p. 6).

It is important to note that online multiplayer computer games involve "networked computers and multiple users" (Allen 2010, p. 232). Therefore, it is possible that the act of one player has a real impact on another player or other players, albeit through the computer-mediated world of the game (Fairfield 2009, p. 825). Yet the question arises whether this real impact can consist of harm. It is not entirely clear what harm entails however. This problem often occurs in top-down reasoning: in hard cases moral judgments usually require that we make the general rules (norms, principles or ideals) themselves more specific (Beauchamp 2003, p. 8).

The notion of harm can be specified as follows. Raz claims that "roughly speaking, one harms another when one's action makes the other person worse off than he was, or is entitled to be, in a way which affects his future wellbeing" (1986, p. 414). Following Raz harm can, for the purposes of the harm principle, be defined as a setback to a morally justifiable (legal) interest (Steel 2008, p. 732). A (legal) interest is considered to be morally justifiable under this definition if a setback to the interest makes a person worse off, in a way which affects his or her well-being.

Does the act of stealing in the virtual world of an online multiplayer computer game cause a setback to a morally justifiable (legal) interest? In order to answer this question it helps to reason the other way around; to take the case as a starting point instead of the general norm or principle. This way of moral reasoning is called bottom-up reasoning. It works as follows. Bottom-up models of moral reasoning include several distinct methodologies, of which casuistry (case-based reasoning) is the most used (Beauchamp 2003, p. 8). In case-based reasoning, the new, particular situation 
is compared to one or more cases to which the general rule does or does not apply (Søraker 2007, p. 342). If the new, particular situation is relevantly similar to the paradigmatic case(s), it should be treated in a similar manner; if it is relevantly different, it should be treated differently (Ibid.). This method of moral reasoning has much in common with legal case-based reasoning (case-law): the decision of a court can be authoritative for other courts hearing cases with similar facts (Beauchamp 2003, p. 9).

Real-life cases in which theft is widely acknowledged as such generally constitute a violation of the property rights of the property owner, which is a setback to legal interests (Stewart 2010, p. 20). Property rights can be seen as morally justifiable legal interests, because a setback to these interests "attack[s] one's entire personal well-being, by attacking the welfare interests necessary to it" (Feinberg 1984, p. 62). This can be explained as follows. According to the prevalent common-sense conception of well-being, wealth is conducive to well-being (Søraker 2010 , p. 263). Property, or at least valuable property, is conducive to wealth. So, a violation of property rights makes a person worse off in a way which affects his or her well-being, because it causes a set-back to his or her wealth. The key harm that is caused by theft is pecuniary loss (Steel 2008, p. 736).

The act of stealing virtual items in the virtual world of an online multiplayer computer game will thus be relevantly similar to real-life cases in which theft is widely acknowledged as such if these virtual items are valuable property, and it will be relevantly different if they are not. Apparently, it is a necessary requirement for an act of stealing to fall under the prohibition on theft that the object(s) stolen is/are valuable property. It is here that we encounter the reconciliation of top-down and bottom-up reasoning. If we focus on the necessary requirement that the case has to meet in order to fall under the scope of the general rule, we neither take the case nor the general rule as a starting point for our moral reasoning. This way of reasoning is called the "coherence method" (Beauchamp 2003 , p. 10). The coherence method enables us to shift back and forth between the general rule and the case via the necessary requirement until they fit each other (Søraker 2007, p. 345).

Yet we can come to the preliminary conclusion that it makes sense, from a moral point of view, to bring the act of stealing virtual items in the virtual world of an online multiplayer computer game under the prohibition on theft if these virtual items count as valuable property in the nonvirtual world. In the next section it will be established whether virtual items can meet this necessary requirement. It should be noted that, thereby, we do not only reach a final conclusion on the question whether it makes sense, from a moral point of view, to see the act of stealing in the virtual world of an online multiplayer computer game as theft, but we will also establish whether it makes sense, from a moral point of view, to see virtual items as requisite objects of theft (objects that can be stolen).

\section{Virtual items: real property, real value?}

In this section it will first be established whether virtual items can count as real property in the non-virtual world. Then, it will be established whether they represent real value in the non-virtual world.

At first glance, one would say that virtual items in the virtual world of an online multiplayer computer game are the property of the company that owns and operates the game. The terms of service (ToS) of most online multiplayer computer games, e.g. those of Habbo and RuneScape, state that all items in the game are the (intellectual) property of the company that owns and operates the game. This determination does not enable us to bring the act of stealing virtual items in the virtual world of the online multiplayer computer game under the scope of the prohibition of theft, however. After all, when one player steals virtual items from another player within the virtual world of an online multiplayer computer game, the property rights of the company that owns and operates the game remain unviolated.

Therefore, the necessary requirement that the act of stealing virtual items in the virtual world of an online multiplayer computer game has to meet in order to fall under the scope of the prohibition on theft needs to be refined. If it can be established that virtual items in the virtual world of an online multiplayer computer game also count as a particular player's (valuable) property in the non-virtual world, the act of stealing them in the virtual world of the computer game constitutes a violation of this player's property rights and it thus makes sense to bring this act under the prohibition on theft. Can virtual items count as a particular player's property in the non-virtual world? Before answering this question it should be noted that the fact that virtual items in the virtual world of an online multiplayer computer game are formally owned by the company that owns and operates the computer game, is not an obstacle to consider them also (valuable) property of a player in the non-virtual world, for the purpose of applying the criminal law (Gerechtshof Leeuwarden, 10 November 2009, LJN: BK2773, BK2764).

(Private) property can be defined as a system that allocates particular objects to particular persons, to the exclusion of others (Waldron 2004, introduction). An object is allocated to a person if some past event of appropriation has established that person as the owner. The past event of appropriation can, for instance, consist of the effort that 
has been put into acquiring the property. In his famous Two Treatises of Government Locke stated:

Whatsoever then he removes out of the state that nature hath provided, and left it in, he hath mixed his labour with, and joined to it something that is his own, and thereby makes it his property.

(Locke 2007 [1689], p. 30, sec. 27)

But, as Hume has pointed out, one may, for instance, also acquire property by a payment ("fortune") (Hume 1978 [1739], p. 489).

Virtual items in the virtual world of an online multiplayer computer game can be brought under the aforementioned definition of property. They are allocated to a particular player of the game, to the exclusion of other players, when they are accessible only through the owner's account with a password and username. The past event of appropriation that established a particular player of an online multiplayer computer game as the owner of a virtual item can consist of the effort that was put into acquiring it. In the virtual world of RuneScape, for instance, players can purchase items, such as a virtual mask and a virtual amulet, by the performance of certain tasks (http://www.runescape. com). The past event of appropriation can also consist of a payment. In the virtual world of Habbo, for instance, players can purchase virtual furniture with "credits", which they can buy with real, non-virtual money (http:// www.habbo.nl; http://www.habbo.com).

In sum, virtual items in the virtual world of an online multiplayer computer game can count as a particular player's property in the non-virtual world. Can they also represent value in the non-virtual world? In order to determine the real, non-virtual value of a virtual item we have to go back to what defined it as property. That is because the value that virtual property represents in the non-virtual world is related to the nature of the event of appropriation by which a person has established him- or herself as the owner.

If a player really needs to pay in order to purchase a virtual item in the virtual world of an online multiplayer computer game, this virtual item represents pecuniary value in the non-virtual world (Rijna 2010, pp. 792-793). As a matter of fact, most things that count as property in the non-virtual world are of pecuniary value. As was established in the last section, the key harm that is caused by theft is pecuniary loss.

Virtual items that cannot be purchased by a payment, but only by effort, such as the virtual mask and the virtual amulet that were at stake in the RuneScape case, cannot represent pecuniary value in the non-virtual world. But they can represent another type of value, which is not conducive to wealth, but to another aspect of well-being. According to Mooradian hedonism is the philosophical theory of well-being that best explains (non-pecuniary) value attributions to virtual entities (2006, p. 688). Hedonism claims that all and only pleasure has value and all and only pain has disvalue for well-being. Both pleasure and pain are understood broadly. Pleasure is taken to include all pleasant experience; pain is taken to include all unpleasant experience (Moore 2004, introduction). Thus, hedonism argues that the constituents of (dis)value are (un)pleasant sensations, feelings and emotions (Mooradian 2006, p. 688).

There are several hedonist accounts of the level or amount of pleasure's value. Bentham claimed, for instance, that the amount of value varies with pleasure's quantitative features: its duration, intensity or strength (as summarized by Moore 2004, $\S 2$ ). Mill thought that the amount of value varies with pleasure's quality; he thought that there are 'higher' and 'lower' pleasures (as summarized by Moore $2004, \S 2$ ). In sum, hedonism reduces value judgments to judgments about "the qualities of sensations and feelings as well as the probability and frequency of their occurence, among other things" (Mooradian 2006, p. 688).

The virtual entities that we encounter in the virtual worlds of online multiplayer computer games cannot provide for sensory pleasures or pains, however. Therefore, their value cannot be explained in ordinary hedonistic terms. As Søraker points out, it is a special kind of hedonism that can explain the value of virtual entities: "Confidence Adjusted Intrinsic Attitudinal Hedonism (CAIAH)" (2010, p. 191). CAIAH assumes that well-being is not enhanced or reduced by sensory pleasures or pains, but by attitudinal pleasures or pains. It is not about physical pleasure or pain, but about the pleasure or pain one takes in something (e.g. if one enjoys playing a computer game). The more confident one is about the pleasure or pain one takes in something, the more conducive or detrimental it is to well-being (Søraker 2010, pp. 191-192).

Media effects studies show that (online multiplayer) computer games elicit real emotions in the non-virtual world (e.g. Järvinen 2009, p. 86). Players take pleasure or pain in gameplay. According to Järvinen the pleasures or pains that are triggered by gameplay are mainly "prospectbased emotions": they are fundamentally related to the goals the game imposes on the players and with which they identify (2009, p. 90). A player can, for instance, become frustrated if $s /$ he does not reach the next level of the game (hedonistic disvalue) and happy if s/he does (hedonistic value). The intensity of these emotions depends on the degree to which the player is "immersed" or "engaged" in the game world (Ibid., p. 92).

Not only events, but also items in the virtual world of an (online multiplayer) computer game can embody prospectbased emotions. Järvinen states: 
A tool that the player can use to her advantage in order to reach the goal $(\ldots)$, represents an object that embodies the solution to the challenge that the goal represents. The object communicates a prospect for the player, and thus, such an instrumental object, and its use, is bound to elicit emotions.

(Järvinen 2009, pp. 99-100).

This can be illustrated as follows. In the virtual world of RuneScape players can develop their abilities in a number of skills, such as fishing, woodcutting or crafting, at different levels. Some of their talents they can use to create items which they can sell to other players. Other talents they can use to perform tasks. By the performance of tasks players can obtain items and points. The richer a player becomes and the more points and items s/he possesses, the more powerful s/he becomes in the game (http://www. runescape.com). So virtual items in the virtual world of RuneScape communicate a prospect for the player: the more of these items s/he possessess, the closer s/he comes to the goal that RuneScape imposes on its players: to become the most powerful player of the game.

Thus, virtual items in the virtual world of an online multiplayer computer game that are purchased by effort can represent hedonistic value in the non-virtual world if they are tools that the player can use to his or her advantage in order to reach the goal of the game. The (amount of) hedonistic value that a virtual item represents in the nonvirtual world, differs from player to player and item to item however. As was established earlier, it depends on the degree to which the player is "immersed" or "engaged" in the game world, how intense the emotions are that the gameplay elicits. The more confident a player is about the pleasure s/he takes in the gameplay, the more pleased s/he is if $\mathrm{s} / \mathrm{he}$ reaches the goal that the computer game imposes on its players and the more hedonistic value a virtual item that can be used for this represents. Of course, the amount of hedonistic value that a virtual item represents also depends on how conducive that particular item is to reaching the goal of the computer game.

In conclusion, virtual items in the virtual world of an online multiplayer computer game can count as a particular player's property in the non-virtual world. They can also represent (pecuniary or hedonistic) value in the non-virtual world. If they do it makes sense, from a moral point of view, to bring the act of stealing them under the prohibition on theft and to count these virtual items, thereby, as requisite objects of theft (objects that can be stolen). ${ }^{1}$

\footnotetext{
${ }^{1}$ An anonymous reviewer suggested the following case as a challenge to the view I present here. In the virtual worlds of certain online multiplayer computer games players can own tools that could be considered illegal in the non-virtual world, e.g. weapons or other tools for violence. Should they count as objects that can be stolen? I
}

\section{Conclusion}

In this paper I have studied both the ontological question whether or not virtual items are "objects" that can be "stolen" and the moral question whether or not they should count as such. I have argued that the act of stealing in the virtual world of an online multiplayer computer game can be seen as a "real institutional activity" and virtual items as "requisite objects" if they have the features that make it sensible to see them as such. Applying Searle's constitutive rule, it can be said, then, that the act of stealing virtual items in the virtual world of an online multiplayer computer game $(\mathrm{X})$ counts as theft $(\mathrm{Y})$ in the non-virtual world (C). Thereby, it is admitted that virtual items (X), count as "objects that can be stolen" $(\mathrm{Y})$ in the non-virtual world (C). I went on to argue that it also makes sense, from a moral point of view, to count them as such under the following conditions.

An act of stealing in the virtual world of an online multiplayer computer game is to be governed by the rules of the game, unless the "magic circle" (a metaphorical line between the fantasy realms of computer games and the non-virtual world) is crossed. The metaphorical line of the magic circle is crossed if the act of stealing constitutes such a grave violation of the rules of the online multiplayer computer game that they do not provide an adequate punishment or if the act of stealing is performed outside the setting of the game, for instance when it involves an out of the game infraction, such as deceit or violence in the non-virtual world. The act of stealing can be brought under the scope of criminal law, then, if it is harmful to others (John Stuart Mill's "harm principle"). An act of stealing in the virtual world of an online multiplayer computer game harms another player, in the sense that the other player is worse off in a way which affects his or her wellbeing, if the object(s) stolen is/are this other player's valuable property in the non-virtual world. Here the questions whether it makes sense to count the act of stealing in the virtual world of an online multiplayer computer game as theft and virtual items as objects that can be stolen in the non-virtual world, become intertwined.

Virtual items can be considered a particular player's property in the non-virtual world if they are allocated to this particular player, to the exclusion of others. A virtual item is allocated to a particular player if some past event of appropriation has established that player as the owner.

\footnotetext{
Footnote 1 continued

do not think that the (legal) status of the real, non-virtual equivalent of a virtual item is of importance for the question whether or not it should count as an object that can be stolen. The real, non-virtual equivalent of a virtual item might be illegal; there also might not be a real, non-virtual equivalent of the virtual item (if it is fictitious, e.g. a magic potion). As long as a virtual item can be considered property worthy of (pecuniary or hedonistic) value in the non-virtual world, it should count as an object that can be stolen.
} 
The past event of appropriation can, for instance, consist of a payment or of the effort that has been put into acquiring the virtual item. The value that virtual items represent in the non-virtual world is related to the nature of the event of appropriation by which a player has established him- or herself as the owner. If a player really needs to pay in order to purchase a virtual item in the virtual world of an online multiplayer computer game, this virtual item represents pecuniary value in the non-virtual world. If the virtual item is acquired by effort, it can represent hedonistic value in the non-virtual world. The constituents of hedonistic value are pleasant emotions. Virtual items can elicit pleasant emotions if they are tools that the player can use to his or her advantage in order to reach the goal of the game. The intensity of the pleasant emotions a virtual item elicits and thus the amount of hedonistic value it represents, depend on the degree to which the player is "immersed" or "engaged" in the virtual world of the online multiplayer computer game. The amount of hedonistic value that a virtual item represents also depends on how conducive the particular item is to reach the goal that the game imposes.

In conclusion, it makes sense to count the act of stealing virtual items in the virtual world of an online multiplayer computer game as theft and, thereby, virtual items as "objects" that can be "stolen" if these virtual items can be considered property with (pecuniary or hedonistic) value in the non-virtual world. I am aware that this conclusion raises other questions. How should we deal with the jurisdictional problems if a player in one country steals a virtual item from a player in another country in the virtual world of an online multiplayer computer game? How should we "measure" the amount of hedonistic value that a particular virtual item represents for a particular player? Answering these questions is beyond the scope of this paper, however. The issue of theft of virtual items in the virtual worlds of online multiplayer computer games is in need of further discussion and analysis from academics not only in the field of computer ethics, but also in the respective fields of law and psychology.

Open Access This article is distributed under the terms of the Creative Commons Attribution Noncommercial License which permits any noncommercial use, distribution, and reproduction in any medium, provided the original author(s) and source are credited.

\section{References}

Allen, C. (2010). Artificial life, artificial agents, virtual realities. In L. Floridi (Ed.), The Cambridge handbook of information and computer ethics (pp. 219-233). Cambridge: Cambridge University Press.
Beauchamp, T. L. (2003). The nature of applied ethics. In R. G. Frey \& C. H. Wellman (Eds.), A companion to applied ethics (pp. 1-16). Malden, MA: Blackwell Publishers.

Brenner, S. W. (2008). Fantasy crime: The role of criminal law in virtual worlds. Vanderbilt Journal of Entertainment and Technology Law, 11(1), 1-97.

Brey, P. (2003). The social ontology of virtual worlds. American Journal of Economics and Sociology, 62(1), 269-282.

Fairfield, J. A. T. (2009). The magic circle. Vanderbilt Journal of Entertainment and Technology Law, 11(4), 823-840.

Feinberg, J. (1984). The moral limits of the criminal law, Vol. 1, Harm to others. New York: Oxford University Press.

Hoekman, J., \& Dirkzwager, C. (2009). Virtuele diefstal: Hoe gegevens toch weer goederen werden. Computerrecht, 148, $158-161$.

Huizinga, J. (1950). Homo ludens. Proeve eener bepaling van het spel-element der cultuur. In L. Brummel et al. (eds.), Johan Huizinga, Verzamelde werken V (Cultuurgeschiedenis III) (pp. 26-246). Haarlem: H. D. Tjeenk Willink and Zoon. (Original work published in 1938).

Hume, D. (1978). A treatise of human nature. Oxford: Clarendon Press. (Original work published in 1739).

Järvinen, A. (2009). Video games as emotional experiences. In B. Perron \& M. J. P. Wolf (Eds.), The video game theory reader 2 (pp. 85-108). New York: Routledge.

Kerr, O. S. (2008) Criminal law in virtual worlds. University of Chicago Legal Forum; GWU Law School Public Law Research Paper No. 391. Available at SSRN: http://ssrn.com/abstract= 1097392.

Locke, J. (2007). Two treatises of government. Saint Louis Park (US): Filiquarian Publishing. (Original work published in 1689).

Mill, J. S. (1865). On liberty. London: Longmans, Green and Co.

Mooradian, N. (2006). Virtual reality, ontology, and value. Metaphilosophy, 37(5), 673-690.

Moore, A. (2004). Hedonism. In Stanford encyclopedia of philosophy. Accessible via $<$ http://plato.stanford.edu $>$.

Moszkowicz, Y. (2009). Een kritische noot bij de 'RuneScape'- en 'Habbohotel'- uitspraken: een illusie is geen goed. Strafblad, Sdu Uitgevers, pp 495-503.

Murphy, J. G., \& Coleman, J. L. (1990). Philosophy of law: An introduction to jurisprudence. Boulder (USA): Westview Press Inc.

Raz, J. (1986). The morality of freedom. Oxford: Clarendon Press.

Rijna, F. (2010). Wat is een virtueel object en kun je het stelen? Nederlands Juristenblad, Afl, 13(647), 790-794.

Salen, K., \& Zimmerman, E. (2004). Rules of play. Game design fundamentals. Cambridge: MIT Press.

Searle, J. R. (1995). The construction of social reality. New York: The Free Press.

Stewart, H. (2010). The limits of the harm principle. Criminal Law and Philosophy, 4, 17-35.

Steel, A. (2008). The harms and wrongs of stealing: The harm principle and dishonesty in theft. UNSW Law Journal, 31(3), $712-737$.

Søraker, J. H. (2007). Real norms, virtual cases: A rationalist, casuistic account of virtual rape. In L. Hinman, P. Brey, L. Floridi, F. Grodzinsky, \& L. Introna (Eds.), Proceedings of CEPE 2007-The 7th international conference of computer ethics: Philosophical enquiry (pp. 340-346). Enschede: Center for Telematics and Information Technology (CTIT).

Søraker, J. H. (2010). The value of virtual worlds: A philosophical analysis of virtual worlds and their potential impact on wellbeing (doctoral dissertation). Enschede: Ipskamp. 


\section{Table of cases}

Hoge Raad, 22 April 2008, LJN: BB7087. Accessible via < http://www.rechtspraak.nl>.
Gerechtshof Leeuwarden, 10 November 2009, LJN: BK2773, BK2764. Accessible via <http://www.rechtspraak.nl>.

Rechtbank Amsterdam, 2 April 2009, LJN: BH9789, BH9790, BH9791. Accessible via <http://www.rechtspraak.nl>. 